\title{
Noninvasive biomarkers for the diagnosis of steatohepatitis and advanced fibrosis in NAFLD
}

\author{
Steven G Pearce ${ }^{\dagger}$, Nirav C Thosani ${ }^{\dagger}$ and Jen-Jung Pan ${ }^{*}$
}

\begin{abstract}
Nonalcoholic fatty liver disease (NAFLD) is the most common cause of abnormal liver enzymes in both adults and children. NAFLD has a histologic spectrum ranging from simple steatosis to nonalcoholic steatohepatitis (NASH), advanced fibrosis, and cirrhosis. It is imperative to distinguish simple steatosis from NASH since the latter has a progressive disease course and can lead to end-stage liver disease. Liver biopsy has been considered as the gold standard for the diagnosis of NASH. However, liver biopsy is invasive, costly, and can rarely cause significant morbidity (risk of morbidity, 0.06-0.35\%; risk of mortality, 0.1-0.01\%). Imaging studies such as ultrasonography, computed tomography, and magnetic resonance imaging have limited sensitivity in detecting steatosis and cannot distinguish steatosis from NASH. Alanine aminotransferase (ALT) has been used as a surrogate marker for liver injuries. However, ALT is not an ideal marker for either diagnosis of NAFLD or distinguishing steatosis from NASH. Better noninvasive biomarkers or panels of biomarkers that are cheaper, reliable, and reproducible are urgently needed for patients with NASH to assist in establishing diagnosis, providing risk information, and monitoring disease progression and treatment response. In this article, we plan to concisely review the current advances in the use of biomarkers for the diagnosis of NASH.
\end{abstract}

Keyword: Biomarker, Noninvasive, NAFLD, NASH, Fibrosis

\section{Introduction}

Nonalcoholic fatty liver disease (NAFLD) is the most common cause of abnormal liver function test results in both adults and children [1,2]. NAFLD in fact covers a histological spectrum ranging from simple steatosis to nonalcoholic steatohepatitis (NASH), advanced fibrosis, and cirrhosis [1]. Simple steatosis without fibrosis or inflammation has a benign clinical course in most but not in all cases without excess mortality [3]. NASH, on the other hand, may have a more progressive course that can lead to cirrhosis in $10-15 \%$ of patients [4]. Survival is lower in patients with NASH based on the findings from long-term longitudinal studies [3,5]. It is therefore imperative to distinguish simple steatosis from NASH in order to provide risk stratification and intervention slowing down disease progression for patients with the latter condition.

Liver biopsy remains the gold standard for making the diagnosis of NASH. However, this procedure is invasive,

\footnotetext{
* Correspondence: jenjung.pan@uth.tmc.edu

${ }^{\dagger}$ Equal contributors

Division of Gastroenterology, Hepatology and Nutrition, Department of Internal Medicine, The University of Texas Health Science Center at Houston, 6431 Fannin Street, MSB 4.234, Houston, TX 77030, USA
}

costly, and is associated with rare but potential complications and sampling errors. Hence it is not suitable as a screening tool for a condition that affects one-third of the American population [6]. Imaging studies such as ultrasonography, computed tomography (CT), and magnetic resonance imaging have been used to diagnose NAFLD. These modalities have the advantages of being noninvasive and can be repetitively performed over a period of time. Nevertheless, none of them have sufficient sensitivity and specificity for staging the disease and cannot distinguish between simple steatosis and NASH with or without fibrosis [6].

Alanine aminotransferase (ALT) has been used as a surrogate marker for liver injury. Several studies suggested that ALT is not an ideal biomarker for either diagnosis of NAFLD or distinguishing simple steatosis from NASH. In a cross-sectional population study, examining hepatic steatosis based on the measurement of hepatic triglyceride content by magnetic resonance spectroscopy, nearly onethird (31\%) of the subjects had hepatic steatosis. Most of the subjects with steatosis (79\%) had normal serum ALT levels [7]. In another study, 58 of 80 (72.5\%) patients who 
had a normal ALT and underwent surgery unrelated to liver diseases had varying degrees of NASH. Among those patients, 26 had fibrosis and 8 had silent cirrhosis [8]. The third study reported that the entire histologic spectrum of NAFLD could be seen in the individuals with normal ALT values. The histological spectrum of NAFLD in people with NAFLD and normal ALT was not significantly different from those with NAFLD and elevated ALT. A low normal ALT value therefore does not guarantee freedom from underlying NASH with advanced fibrosis [9].

As mentioned earlier, the current available tests have significant limitations in distinguishing simple steatosis from NASH, which has important clinical implications. Better noninvasive biomarkers or panels of biomarkers that are cheaper, reliable, and reproducible are urgently needed for patients with NASH to assist in establishing diagnosis, providing risk information, and monitoring disease progression and treatment response. In this article, we plan to concisely review the current advances in the use of biomarkers for the diagnosis of NASH.

\section{Proinflammatory markers and NASH}

NAFLD is considered to be the hepatic manifestation of metabolic syndrome (MetS) [10]. Obesity, a common feature of NAFLD and MetS, is associated with a chronic and subacute inflammatory state that is both systemic and focally localized in certain tissues such as liver. Consistent with the potential roles of inflammation, serum levels of proinflammatory cytokines are elevated in obese subjects [11]. NASH is a progressive form of NAFLD where in addition to simple steatosis, inflammation, hepatocyte ballooning, and sometimes, fibrosis are observed [12]. It is therefore of great interest to determine if $\mathrm{NASH}$ can be distinguished from simple steatosis by using proinflammatory biomarkers. Below we will discuss the current findings of the use of proinflammatory biomarkers for the diagnosis of NASH.

\section{Tumor necrosis factor alpha (TNF-a)}

TNF- $\alpha$ plays an important role in insulin resistance, the pathognomonic feature of MetS, through inhibiting the tyrosine kinase activity of the insulin receptor [13]. Abiru et al. reported that patients with NASH had significantly higher serum TNF- $\alpha$ and its soluble receptor (sTNFR1) than those with simple steatosis, although they did not provide a cutoff value of the cytokine for clinical use [14]. A recent study further reported that patients with NASH had higher levels of TNF- $\alpha$ messenger ribonucleic acid (mRNA) than healthy controls. The authors proposed a TNF- $\alpha$ mRNA cutoff value of $100 \mathrm{ng} / \mathrm{mL}$ predicted NASH [area under receiver operating characteristic curves (AUROC) 0.685, sensitivity $66.7 \%$, specificity $74.1 \%$ ] [15]. The role of TNF- $\alpha$ in $\mathrm{NASH}$ is further supported by the beneficial effects of pentoxifylline, an antagonizer of TNF- $\alpha$, on biochemical and histological activity associated with NASH [16-18].

\section{Interleukin-6 (IL-6)}

IL-6 is implicated in insulin resistance, at least in part, through the induction of suppressor of cytokine signaling-3 in liver [19]. Several studies have reported a strong association between IL-6 and NASH. In a pilot study with a small cohort, patients with NASH received special diet plus exercise with or without antioxidant vitamin E (800 IU/day for 6 weeks). Plasma IL-6 levels were significantly higher in patients with NASH and the levels decreased with the therapy [20]. Not only the cytokine itself, but its soluble receptor is also significantly increased in patients with NASH than those with simple steatosis [14]. No cutoff value of the cytokine for differentiating NASH from simple steatosis was provided from either one of the studies. In the third small cohort study, morbidly obese patients were divided into 3 groups based on the histologic findings: non-NASH, probable NASH, and NASH. IL-6 level was correlated with the degree of steatosis until the patients met the criteria of NASH when their blood IL-6 levels decreased. Multivariate logistic regression analysis identified the level of IL-6 $>4.81 \mathrm{pg} / \mathrm{mL}$ [odds ratio (OR): 33.7, 95\% confidence interval (CI): 1.7-680.7, $\mathrm{p} \leq 0.022$ ] as an independent predictor of the degree of steatosis but not of NASH [21]. In the fourth study, NASH could be well distinguished from simple steatosis when using the cutoff value of IL-6 at $4.6 \mathrm{pg} / \mathrm{mL}$ (AUROC 0.817, sensitivity 58.1\%, specificity $100 \%)$. The authors concluded that IL-6 was highly specific in confirming the absence of NASH at normal values [22].

\section{C-reactive protein (CRP)}

CRP levels were elevated in NAFLD patients compared with controls matched by age and body mass index (BMI) and hence were reported to be an independent risk factor for NAFLD [23]. However, the study was limited by the lack of histologic diagnosis since NAFLD was diagnosed based on elevated ALT and sonographic evidence of fatty liver. It is still controversial whether CRP can differentiate NASH from simple steatosis. For example, high-sensitivity CRP (hs-CRP) levels were significantly higher in patients with NASH compared with those with steatosis in a Japanese study [24]. In addition, hs-CRP levels were significantly elevated in patients with $\mathrm{NASH}$ and advanced fibrosis compared with those with $\mathrm{NASH}$ and mild fibrosis. However, there was no relation between serum hs-CRP levels and either hepatic steatosis or necroinflammation grade. The AUROC for distinguishing between NASH and steatosis using hs-CRP was 0.833 [24]. In a Romanian study, CRP had an excellent performance in predicting the presence of NASH using a cutoff value of $3.5 \mathrm{mg} / \mathrm{L}$ (AUROC 0.906, sensitivity 
$82 \%$, specificity $88 \%)$. CRP, however, was not a predictor of severe fibrosis $(\mathrm{F} \geq 3)$ in that study [25].

In contrast, a small cohort study (18 patients with $\mathrm{NASH}$ ) reported that there was no correlation of CRP levels with either the degree of hepatic steatosis, inflammation, or the stage of liver fibrosis despite the fact that NASH patients had significantly higher CRP levels than 16 controls [26]. Similar to the previous study, an Australian group reported that patients with $\mathrm{NASH}$ and simple steatosis had similar hs-CRP levels. No relationship existed between hs-CRP levels and the grades of hepatic steatosis, necroinflammation, and fibrosis [27]. Both studies are underpowered due to inadequate sample sizes.

CRP may be a marker of hepatic steatosis but not of severity of NAFLD in obese patients [28].

\section{Pentraxin 3 (PTX3)}

PTX3 is a prototypic member of the long chain pentraxin family and a newly discovered marker of the acute phase inflammatory response. PTX3 is structurally related to, but distinct from classic members of the short chain pentraxin family, including CRP [29]. Yoneda et al. [29] first reported that the plasma PTX3 level was significantly higher in patients with NASH than those with simple steatosis or healthy controls. No significant difference of plasma PTX3 levels was observed between the simple steatosis and control groups. A stepwise increase in plasma PTX3 levels was found as the stages of hepatic fibrosis increased. PTX3, however, was not related to either hepatic steatosis or necroinflammation grade. Using $1.61 \mathrm{ng} / \mathrm{mL}$ as a cutoff value, PTX3 had a fair performance in differentiating NASH from simple steatosis (AUROC 0.755 , sensitivity $66.7 \%$, specificity $78.6 \%$ ). Using $2.45 \mathrm{ng} / \mathrm{mL}$ as a cutoff value, PTX3 had a good performance in distinguishing stage 3-4 from stage 0-2 NAFLD (AUROC 0.850, sensitivity 70.6\%, specificity 94.3\%) [29].

\section{Ferritin}

Increased ferritin but normal transferrin saturation is frequently found in patients with hepatic steatosis. The simultaneous disorder of iron and glucose and/or lipid metabolism, in most of the cases associated with insulin resistance, is responsible for persistent hyperferritinemia and identifies patients at risk for NASH [30]. Indeed, serum ferritin level was significantly higher in the NASH patients than those with simple steatosis, according to a Japanese study [31]. In that study, the serum ferritin level was related with insulin resistance. The performance of serum ferritin for distinguishing NASH from simple steatosis was fair (AUROC 0.732) and the optimal cutoff value was $196 \mathrm{ng} / \mathrm{mL}$ with a sensitivity $64.2 \%$ and specificity $76.5 \%$. In another study, the performance of serum ferritin for detecting NASH was improved (AUROC
0.82) when using a higher cutoff value $240 \mathrm{ng} / \mathrm{mL}$ with the price of losing specificity (sensitivity $91 \%$, specificity $70 \%$ ) [32]. In a recent large cohort study using gender-specific cutoff values (> $300 \mathrm{ng} / \mathrm{mL}$ in women and $>450 \mathrm{ng} / \mathrm{mL}$ for men), serum ferritin levels greater than 1.5 times of upper limit of normal was associated with hepatic iron deposition, a diagnosis of NASH, and worsened histologic activity, and is an independent predictor of advanced hepatic fibrosis among patients with NAFLD. The authors concluded that serum ferritin is useful to identify NAFLD patients at risk for NASH and advanced fibrosis [33]. A recent report from Japan stated that the extent of serum ferritin elevations did not predict the stage of NAFLD although hyperferritinemia was common in NAFLD patients. The study is limited by a possible selection bias since only $19 \%$ of the study subjects had a histologic diagnosis [34].

In summary, a variety of proinflammatory biomarkers such as TNF- $\alpha$, IL-6, CRP, and ferritin have been studied for their associations with NASH. Their performance in distinguishing NASH from simple steatosis is either fair or good but not excellent. Controversies of the association of each proinflammatory marker with NASH exist and well accepted cutoff values of each marker remain unknown.

\section{Constituents of extracellular matrix (ECM)}

Liver fibrosis is one of the features of NASH [12]. The constituents of ECM are expected to be released into circulation during turnover of fibrosis in the liver. It is therefore reasonable using such markers to differentiate NASH from simple steatosis, especially those with significant liver fibrosis.

Yoneda et al. reported that marked elevation of serum hyaluronic acid (HA) and type IV collagen 7S domain, both ECM components, occurred in NASH patients with advanced fibrosis compared to those with mild fibrosis [24]. Serum HA levels were also markedly elevated in patients with NASH than with steatosis only. No cutoff value of either marker was provided in the study [24]. Another study reported that the best cutoff values to detect NASH using ROC analysis were $\geq 43 \mathrm{ng} / \mathrm{mL}$ for HA (AUROC 0.797) and $\geq 5 \mathrm{ng} / \mathrm{mL}$ for type IV collagen $7 \mathrm{~S}$ domain (AUROC 0.828). The positive predictive value (PPV) for detecting NASH can be as high as $97.1 \%$ when both markers are greater than the cutoffs. In addition, the best cutoff values to detect severe fibrosis were $\geq 50 \mathrm{ng} / \mathrm{mL}$ for HA (AUROC 0.797) and $\geq 5 \mathrm{ng} / \mathrm{mL}$ for type IV collagen 7S domain (AUROC 0.817). The study reported that severe hepatic fibrosis is unlikely to be present if both markers are concomitantly less than the cutoffs [35]. In a study including only NASH patients, those with liver fibrosis had significantly higher serum HA and laminin levels than those without fibrosis. The best cutoff value was $148.8 \mathrm{ng} / \mathrm{mL}$ for HA (AUROC 0.975, 
sensitivity $97.5 \%$, specificity $95.7 \%)$ and was $292.5 \mathrm{ng} / \mathrm{mL}$ for laminin (AUROC 0.789 , sensitivity $73.9 \%$, specificity 74.1\%). The authors concluded that HA could be a predictive factor of the presence and stage of liver fibrosis in $\mathrm{NASH}$. Laminin could be used to diagnose liver fibrosis but has no value in staging [36].

In contrast to the aforementioned findings, Malik et al. reported that there was no difference in levels of fibrosis markers such as HA, YKL-40, and tissue inhibitor of metalloproteinase 1 (TIMP1) between patients with NASH and with simple steatosis [37]. Similar to the previous study, a recent study reported that neither HA, TIMP1, YKL-40, nor collagen IV was associated with a histologic diagnosis of NASH. Pro-collagen III (PIIINP) was the only marker that was correlated with the total NAFLD activity score (NAS) and its constituent components. PIIINP was able to discriminate between patients with simple steatosis and those with NASH or advanced fibrosis with AUROC 0.85-0.87 [38].

In summary, ECM constituents seem to be decent markers for the detection of NASH although not without controversy. These markers are limited for routine use as they are not readily available in clinical laboratories. For better detection performances, these markers are often incorporated into diagnostic panels that are composed of several biomarkers. We will discuss these panels later in this review.

\section{Apoptosis markers}

Apoptosis is a common mechanism of liver injury. Feldstein et al. [39] reported that the number of apoptotic cells was significantly increased in liver biopsy specimens from patients with NASH compared with those with simple steatosis and healthy controls. Immunohistochemistry demonstrated active caspases 3 and 7 in NASH specimens, confirming the occurrence of apoptosis in this condition. The apoptotic pathway is composed of two arms: the intrinsic pathway (initiated by cellular stress) and the extrinsic pathway (stimulated through a death receptor-mediated process). Both pathways are suspected to be involved in the pathogenesis of NASH [40]. In the final common step of apoptosis, the effector caspases (especially caspase 3 and caspase 7) are activated and cleave a number of different substrates inside the cell, including cytokeratin 18 (CK18), the major intermediate filament protein in the liver [41]. Plasma CK18 fragments were found to be markedly increased in patients with NASH $(n=21)$ than those with simple steatosis $(n=8)$ or normal controls $(n=10)$ [median (interquartile range): $765.7 \mathrm{U} / \mathrm{L}$ (479.6-991.1), 202.4 U/L (160.4-258.2), $215.5 \mathrm{U} / \mathrm{L}$ (150.2-296.2), respectively; $\mathrm{p}<0.001$ ] [41]. A cutoff value of $395 \mathrm{U} / \mathrm{L}$ performed excellently for the diagnosis of NASH (AUROC 0.93, sensitivity 85.7, specificity 99.9\%). For every $50 \mathrm{U} / \mathrm{L}$ increase in CK18 levels, the likelihood of having "definitive NASH" increased 86\% (OR 1.86; 95\% CI 1.23-2.82) [41]. By studying a larger cohort, the same group validated the significantly higher plasma CK18 fragments in patients with NASH $(n=69)$ versus those without NASH $(n=44)$ and borderline diagnosis $(\mathrm{n}=26)$ [median $\left(25^{\text {th }}, 75^{\text {th }}\right.$ percentile), 335 (196, 511), 194 (151, 270), 200 (148, 284), respectively; $\mathrm{p}<0.001]$. The AUROC for NASH diagnosis was estimated to be 0.83 [42]. A Greek study reported that fragmented CK18 levels had a good diagnostic accuracy for differentiating patients with NASH $(n=30)$ from those with simple steatosis $(n=28$; AUROC 0.87$)$. Levels of CK18 fragments $\geq 225 \mathrm{U} / \mathrm{L}, \geq 250 \mathrm{U} / \mathrm{L}$, or $\geq 300 \mathrm{U} / \mathrm{L}$ had sensitivity of $70 \%, 60 \%$, or $53 \%$; specificity of $82 \%$, $93 \%$, or $100 \%$; PPV of $84 \%, 95 \%$, or $100 \%$; and negative predictive value (NPV) of $73 \%, 69 \%$, or $67 \%$ for the diagnosis of $\mathrm{NASH}$, respectively [43]. Using paired liver biopsies, serum CK18 fragment levels correlated with NAS in NAFLD patients [44]. The finding suggests that serum CK18 fragment levels can be used for monitoring NAFLD disease activity and treatment responses.

Two studies suggested that CK18 fragments may have a better performance for the diagnosis of NASH when combining with other tests $[45,46]$. First, a Turkish study reported that serum CK18 fragments had a fair performance in discriminating $\mathrm{NASH}$ from non-NASH (i.e., borderline NASH, simple steatosis, normal tissue) when using 121.6 U/L as the cutoff value (AUROC 0.787, sensitivity $60 \%$, specificity 97.4). Using $243.8 \mathrm{U} / \mathrm{L}$ as the cutoff value, total serum CK18 levels had a better sensitivity and worse specificity than its apoptotic fragments for the diagnosis of NASH (AUROC 0.809, sensitivity 68.9, specificity 81.6). When combining CK18 with the liver attenuation on CT in Hounsfield units, both total CK18 and its apoptotic fragments had higher sensitivity $(83.3 \%$ and $86.1 \%$, respectively) for definitive NASH. The authors suggested that measurement of different forms of CK18 in combination with CT has greater diagnostic utility for the identification of patients with definitive NASH than the use of either test alone [45]. Second, a study from a group in Hong Kong reported a 2-step approach using CK18 fragments and fibroblast growth factor 21 (FGF21) further improved the accuracy in diagnosing NASH. In that study, at cutoffs of 203 and $670 \mathrm{U} / \mathrm{L}$, serum CK18 fragments had a 71\% NPV and 77\% PPV to exclude and diagnose NASH. A 2-step approach measuring CK18 followed by FGF21 further improved the NPV to $74 \%$ and PPV to $82 \%$ [46].

Joka et al. [47] reported that both total serum CK18 and CK18 fragments could accurately differentiate healthy controls or simple steatosis from NASH and discriminate patients with different fibrosis stages from healthy controls. However, total CK18 levels had a better diagnostic performance and even differentiation between lower fibrosis stages as well as between healthy 
individuals and patients with simple steatosis than the apoptotic CK18 fragments [47].

In summary, $\mathrm{NASH}$ is associated with an increase in apoptotic activity in the liver. CK18 fragments are promising noninvasive biomarkers for the diagnosis of NASH. Based on the data from the paired biopsy study, serum levels of CK18 fragments can be possibly used to monitor liver disease activity and responses to treatment in patients with NASH.

\section{Diagnostic panels for NASH and advanced liver fibrosis}

The diagnostic panels for NAFLD can be divided to two categories, one for the prediction of NASH and the other for the detection of liver fibrosis.

\section{Panels for the detection of NASH}

Different diagnostic panels for NASH are shown in Table 1. According to the HAIR scoring system, a weighted score of 2 or 3 is highly predictive of NASH. However, the study was confined to those with a BMI $>35 \mathrm{~kg} / \mathrm{m}^{2}$ and the results may not be applicable to those with a lower BMI [48]. In the model reported by Palekar et al., patients with three or more of the following six characteristics are more likely to have NASH than simple steatosis: female gender, age $\geq 50$ years, BMI $\geq 30 \mathrm{~kg} / \mathrm{m}^{2}$, aspartate aminotransferase (AST) $\geq 45 \mathrm{U} / \mathrm{L}$, AST/ALT ratio $\geq 0.8$, and $\mathrm{HA} \geq 55 \mathrm{mcg} / \mathrm{L}$ [49]. Combining 13 clinical and biochemical parameters, the NashTest only had a fair performance (AUROC 0.78 ) but a very good specificity (94\%) for predicting NASH [50]. Comparing with the NashTest, Gholam et al. was able to predict NASH in a severely obese cohort (BMI $\geq 40 \mathrm{~kg} / \mathrm{m}^{2}$ ) by simply using two markers, AST and the presence of diabetes (AUROC 0.82) [51].

Obstructive sleep apnea has been shown to improve diagnostic accuracy of the panels for NASH $[52,53]$. The NASH Clinical Scoring System for Morbid Obesity is consisted of six components including hypertension, type 2 diabetes, AST $\geq 27 \mathrm{U} / \mathrm{L}$, ALT $\geq 27 \mathrm{U} / \mathrm{L}$, sleep apnea, and non-black race. Two points are assigned to non-black race and one point is assigned to the rest of the five components. The probability of NASH is determined based on the summed points. A cohort of morbidly obese patients $(n=186)$ was divided into four categories based on the probability of NASH (low, intermediate, high, and very high). Both the PPV of the very high-risk category and the NPV of the low-risk category for NASH were $93 \%$ and the AUROC was 0.8 [52]. A simplified scoring model based on only four variables including type 2 diabetes, ALT $>40$ $\mathrm{U} / \mathrm{L}$, triglyceride $>150 \mathrm{mg} / \mathrm{dL}$, and obstructive sleep apnea was reported by Ulitsky et al. [53]. Similar to the design of the previous study, two points are assigned to diabetes and one point is assigned to the other three variables. A cohort of morbidly obese patients $(n=235)$ was divided into four groups based on the risk of NASH determined by the summed points (low, intermediate, high, and very high). The model performed similarly to the previous study (AUROC 0.76 vs. 0.8) [52,53]. Both studies suggested that a liver biopsy should be recommended for morbidly obese individuals who are in the high and very high-risk categories for NASH. On the other hand, a liver biopsy can be delayed or avoided for individuals with a low risk of NASH $[52,53]$.

Shimada et al. reported that approximately $90 \%$ of the patients with early-stage NASH can be predicted by a combined evaluation of the serum adiponectin level, homeostasis model assessment of insulin resistance (HOMA-IR), and serum type IV collagen 7S level [54]. Both adiponectin and resistin are adipokines mainly produced by adipose tissues and both are involved in insulin resistance. Hypoadiponectinemia is commonly seen in patients with NAFLD [55]. Tarek et al. developed a panel that consisted of 2 apoptosis markers (CK18 fragments and soluble Fas) for NASH [56]. In the initial cohort that included patients suspicious for having NASH, the panel performed quite well with an AUROC 0.93. In the validation cohort that included morbidly obese patients only, the panel still had a fair performance with an AUROC 0.79. The high AUROC in the validation group indicated that this panel provides reproducible results even for a highly distinct group of patients [56].

Given the complexity of the pathogenesis of NASH, it is likely that multiple pathways may play critical roles in the development of the disease. Younossi et al. therefore developed the NASH diagnostics model that includes two apoptosis markers (apoptosis- and necrosis-derived CK18 fragments) and two adipokines (adiponectin and resistin) [57]. If the model were used to minimize the use of liver biopsies at the threshold of $0.2085,79.2 \%$ of the study patients could avoid the invasive procedure. Again, the study subjects were morbidly obese and the study results may not be generalized to non-obese population [57]. Sookoian et al. designed a diagnostic panel based on a composite index using nine markers derived from both clinical and routine laboratory data [58]. Considering a model patient with all the positive tests, the post-test probability for NASH would be $99.5 \%$. In the same way, considering a model with all negative tests, the post-test probability for NASH would be negligible $(0.3 \%)$. Nevertheless, the performance of the model was only fair (AUROC 0.795) [58].

Based on the head-to-head comparison studies, two panels were reported outperforming several other existed panels previously mentioned. First, the NAFIC scoring system using the following markers: serum ferritin ( $\geq 200 \mathrm{ng} / \mathrm{mL}$ for female; $\geq 300 \mathrm{ng} / \mathrm{mL}$ for male), fasting insulin $(\geq 10 \mu \mathrm{U} / \mathrm{mL})$, and type IV collagen $7 \mathrm{~S}$ ( $\geq 5 \mathrm{ng} / \mathrm{mL}$ ), outperformed the HAIR scoring system 
Table 1 Accuracy of diagnostic panels for NASH

\begin{tabular}{|c|c|c|c|c|c|c|c|c|}
\hline Reference & Biomarkers & $\mathbf{N}$ & AUROC & Cutoff value & Se (\%) & Sp (\%) & PPV (\%) & NPV (\%) \\
\hline \multirow[t]{2}{*}{ Dixon [48] } & HAIR score & 105 & 0.90 & score $>2$ & 80 & 89 & $\mathrm{n} / \mathrm{a}$ & $\mathrm{n} / \mathrm{a}$ \\
\hline & (hypertension, ALT>40 U/L, IR index>5) & & & & & & & \\
\hline \multirow[t]{2}{*}{ Palekar [49] } & age $\geq 50$ years, female gender, $A S T \geq 45 \mathrm{U} / \mathrm{L}$, & 80 & 0.76 & score $\geq 3$ & 73.7 & 65.7 & 68.2 & 71.4 \\
\hline & $\mathrm{BMI} \geq 30 \mathrm{~kg} / \mathrm{m}^{2}$, AAR ratio $\geq 0.8, \mathrm{HA} \geq 55 \mathrm{mcg} / \mathrm{L}$ & & & & & & & \\
\hline \multirow[t]{4}{*}{ Poynard [50] } & NashTest & 257 & 0.78 & $\mathrm{n} / \mathrm{a}$ & 33 & 94 & 66 & 81 \\
\hline & (age, sex, height, weight, triglyceride, GGT, & & & & & & & \\
\hline & cholesterol, alpha2macroglobulin, AST, ALT, & & & & & & & \\
\hline & apolipoprotein A1, haptoglobin, total bilirubin) & & & & & & & \\
\hline Gholam [51] & AST, presence of diabetes & 97 & 0.82 & 8.22 & 76 & 66 & $\mathrm{n} / \mathrm{a}$ & $\mathrm{n} / \mathrm{a}$ \\
\hline \multirow[t]{4}{*}{ Campos [52] } & NASH Clinical Scoring System for Morbid & 186 & 0.80 & $0-2$ & & & 7 & 93 \\
\hline & obesity (hypertension, type 2 diabetes, & & & $3-4$ & & & 27 & 73 \\
\hline & AST $\geq 27 \mathrm{U} / \mathrm{L}, \mathrm{ALT} \geq 27 \mathrm{U} / \mathrm{L}$, sleep apnea, & & & 5 & & & 59 & 41 \\
\hline & non-black race) & & & $6-7$ & & & 93 & 7 \\
\hline \multirow[t]{4}{*}{ Ulitsky [53] } & diabetes, ALT >40 U/L, triglyceride $>150$ & 253 & 0.76 & $0-1$ & & & 10.6 & 89.4 \\
\hline & $\mathrm{mg} / \mathrm{dL}$, sleep apnea & & & $2-3$ & & & 24.7 & 75.3 \\
\hline & & & & 4 & & & 60 & 40 \\
\hline & & & & 5 & & & 75 & 25 \\
\hline \multirow[t]{2}{*}{ Shimada [54] } & adiponectin $\leq 4 \mathrm{mcg} / \mathrm{mL}, \mathrm{HOMA}-\mathrm{R} \geq 3$, & 85 & $\mathrm{n} / \mathrm{a}$ & all 3 +ive & 94 & 74 & 94 & 74 \\
\hline & type IV collagen $7 \mathrm{~S} \geq 5 \mathrm{ng} / \mathrm{mL}$ & & & & & & & \\
\hline Tarek [56] & CK18 fragments, sFas & 95 & 0.93 & -0.5509 & 88 & 89 & $\mathrm{n} / \mathrm{a}$ & $\mathrm{n} / \mathrm{a}$ \\
\hline \multirow[t]{3}{*}{ Younossi [57] } & NASH Diagnostics & 101 & 0.908 & 0.2772 & 94.5 & 70.2 & 60 & 97.1 \\
\hline & (cleaved and intact CK18 levels, & & & & & & & \\
\hline & serum adiponectin and resistin levels) & & & & & & & \\
\hline \multirow[t]{2}{*}{ Sookoain [58] } & BMI, waist circumference, ALT, AST, AP, & 101 & 0.795 & $\mathrm{n} / \mathrm{a}$ & $\mathrm{n} / \mathrm{a}$ & $\mathrm{n} / \mathrm{a}$ & $\mathrm{n} / \mathrm{a}$ & $\mathrm{n} / \mathrm{a}$ \\
\hline & GGT, HOMA, CRP, SICAM-1 & & & & & & & \\
\hline \multirow[t]{4}{*}{ Sumida [59] } & NAFIC score & $177^{\dagger}$ & $0.851^{\dagger}$ & 1 & 94 & 48 & 31 & 86 \\
\hline & [serum ferritin ( $\geq 200 \mathrm{ng} / \mathrm{mL}$ for female, & & & 2 & 66 & 91 & 90 & 67 \\
\hline & $\geq 300 \mathrm{ng} / \mathrm{mL}$ for male), fasting insulin $\geq 10$ & $442^{*}$ & $0.782^{*}$ & 1 & 88 & 43 & 66 & 75 \\
\hline & $\mu \mathrm{U} / \mathrm{mL}$, type IV collagen $\geq 5 \mathrm{ng} / \mathrm{mL}]$ & & & 2 & 60 & 87 & 85 & 64 \\
\hline \multirow[t]{3}{*}{ Younossi [60] } & NAFLD Diagnostic Panel & 79 & 0.81 & 0.221 & 91.2 & 47.4 & 60.8 & 85.7 \\
\hline & (diabetes, gender, BMI, triglycerides, & & & 0.3641 & 79.4 & 73.7 & 73 & 80 \\
\hline & apoptotic and necrotic CK18 fragments) & & & 0.6183 & 44.1 & 92.1 & 83.3 & 64.8 \\
\hline
\end{tabular}

AUROC, area under receiver operator characteristic curve; Se, sensitivity; Sp, specificity; PPV, positive predictive value; NPV, negative predictive value; ALT, alanine aminotransferase; IR, insulin resistance; AST, aspartate aminotransferase; BMI, body mass index; AAR, AST/ALT ratio; HA, hyaluronic acid; GGT, gamma-glutamyl transpeptidase; HOMA-IR, homeostasis model assessment of insulin resistance; AP, alkaline phosphatase; CRP, C-reactive protein; $n / a$, not available.

${ }^{\dagger}$ Estimation group; ${ }^{¥}$ Validation group.

[48] and the scoring system developed by Palekar et al. [49] and Gholam et al. [51] for differentiating NASH from simple steatosis [59]. The study results, however, may not be adaptable for NAFLD patients of other races since all participants of the study were Japanese. Second, the NAFLD Diagnostic Panel using five markers: diabetes, gender, BMI, triglycerides, apoptotic and necrotic CK18 fragments, had a better performance than the NASH Diagnostics for predicting histologic NASH [60]. The study participants in both studies had similar BMIs and both panels included CK18 fragments as a marker $[57,60]$.

\section{Panels for the detection of advanced liver fibrosis}

Several diagnostic panels have been developed for the prediction of significant liver fibrosis (Table 2). Angulo et al. suggested that NASH patients who are older ( $\geq 45$ years), obese (BMI $>31.1 \mathrm{~kg} / \mathrm{m}^{2}$ for male, $>32.3 \mathrm{~kg} / \mathrm{m}^{2}$ for female), and suffer from diabetes mellitus are at greatest risk of progressing to cirrhosis with its consequent 
Table 2 Accuracy of diagnostic panels for advanced liver fibrosis

\begin{tabular}{|c|c|c|c|c|c|c|c|c|}
\hline Reference & Biomarkers & $\mathrm{N}$ & AUROC & Cutoff value & Se (\%) & Sp (\%) & PPV (\%) & NPV (\%) \\
\hline \multirow[t]{2}{*}{ Angulo [61] } & age $\geq 45$ years, obesity $(\mathrm{BMl}>31.1$ for male, & 144 & $\mathrm{n} / \mathrm{a}$ & $\mathrm{n} / \mathrm{a}$ & $\mathrm{n} / \mathrm{a}$ & $\mathrm{n} / \mathrm{a}$ & $\mathrm{n} / \mathrm{a}$ & $\mathrm{n} / \mathrm{a}$ \\
\hline & $>32.3$ for female), diabetes, AAR>1 & & & & & & & \\
\hline \multirow[t]{5}{*}{ Ratziu [62] } & BAAT score & 93 & 0.84 & 0 & 100 & 11 & 33 & 100 \\
\hline & $\left(\mathrm{BMI} \geq 28 \mathrm{~kg} / \mathrm{m}^{2}\right.$, age $\geq 50$ years, $A L T \geq 2 x \cup L N$ & & & 1 & 100 & 47 & 45 & 100 \\
\hline & triglycerides $\geq 1.7 \mathrm{mmol} / \mathrm{L}$ ) & & & 2 & 71 & 80 & 61 & 86 \\
\hline & & & & 3 & 14 & 100 & 100 & 73 \\
\hline & & & & 4 & 0 & 100 & 0 & 70 \\
\hline Rosenberg & Original European Liver Fibrosis panel & 61 & 0.87 & 0.375 & 89 & 96 & 80 & 98 \\
\hline [63] & (age, HA, TIMP1, PIIINP) & & & 0.462 & 78 & 98 & 87 & 96 \\
\hline \multirow[t]{2}{*}{ Guha [64] } & Enhanced Liver Fibrosis panel & 192 & 0.90 & 0.3576 & 80 & 90 & 71 & 94 \\
\hline & (HA, TIMP1, PIIINP) & & & & & & & \\
\hline Gholam [51] & ALT, $\mathrm{HbA1C}$ & 97 & 0.90 & 6.6 & 83 & 82 & $n / a$ & $\mathrm{n} / \mathrm{a}$ \\
\hline \multirow[t]{3}{*}{ Ratziu [65] } & FibroTest & 267 & 0.81 & 0.3 & 77 & 77 & 54 & 90 \\
\hline & (a2 macroglobulin, haptoglobin, GGT, & & & 0.7 & 15 & 98 & 73 & 76 \\
\hline & Total bilirubin, apolipoprotein A1) & & & & & & & \\
\hline \multirow[t]{4}{*}{ Angulo [66] } & NAFLD Fibrosis Score & 733 & 0.84 & $<-1.455^{\dagger}$ & 82 & 77 & 56 & 93 \\
\hline & (age, hyperglycemia, BMI, platelet count, & & & $>0.676^{\dagger}$ & 51 & 98 & 90 & 85 \\
\hline & albumin, AAR) & & & $<-1.455^{¥}$ & 77 & 71 & 52 & 88 \\
\hline & & & & $>0.676^{¥}$ & 43 & 96 & 82 & 80 \\
\hline \multirow[t]{2}{*}{ Harrison [67] } & BARD score & 827 & 0.81 & $2-4$ & & & 43 & 96 \\
\hline & (BMI $\geq 28 \mathrm{~kg} / \mathrm{m}^{2}, A A R \geq 0.8$, diabetes) & & & & & & & \\
\hline \multirow[t]{3}{*}{ Cales [68] } & Fibrometer NAFLD & 235 & 0.943 & & 78.5 & 95.9 & 87.9 & 92.1 \\
\hline & (glucose, AST, ferritin, ALT, body weight, & & & & & & & \\
\hline & age) & & & & & & & \\
\hline \multirow[t]{2}{*}{ Shah [69] } & FIB4 index & 541 & 0.802 & $<1.30$ & 74 & 71 & 43 & 90 \\
\hline & (age, ALT, AST, platelet count) & & & $>2.67$ & 33 & 98 & 80 & 83 \\
\hline \multirow[t]{4}{*}{ Sumida [59] } & NAFIC score & 619 & 0.834 & 0 & 95 & 33 & 32 & 96 \\
\hline & [serum ferritin ( $\geq 200 \mathrm{ng} / \mathrm{mL}$ for female, & & & $2-4$ & 84 & 74 & 52 & 93 \\
\hline & $\geq 300 \mathrm{ng} / \mathrm{mL}$ for male), fasting insulin $\geq 10$ & & & & & & & \\
\hline & $\mu \mathrm{U} / \mathrm{mL}$, type IV collagen $7 \mathrm{~S} \geq 5 \mathrm{ng} / \mathrm{mL}]$ & & & & & & & \\
\hline \multirow[t]{3}{*}{ Younossi [60] } & NAFLD Diagnostic Panel & 79 & 0.80 & 0.2188 & 90.91 & 43.59 & 57.7 & 85 \\
\hline & (diabetes, gender, BMI, triglycerides, & & & 0.4242 & 60.61 & 71.79 & 64.5 & 68.3 \\
\hline & apoptotic and necrotic CK18 fragments) & & & 0.5689 & 51.52 & 89.74 & 81 & 68.6 \\
\hline
\end{tabular}

AUROC, area under receiver operator characteristic curve; Se, sensitivity; Sp, specificity; PPV, positive predictive value; NPV, negative predictive value; ALT, alanine aminotransferase; AST, aspartate aminotransferase; BMI, body mass index; AAR, AST/ALT ratio; HA, hyaluronic acid; GGT, gamma-glutamyl transpeptidase; TIMP1, tissue inhibitor of metalloproteinase 1; PIIINP, amino-terminal propeptide of type III collagen; ULN, upper limit of normal; n/a, not available.

${ }^{\dagger}$ Estimation group; ${ }^{¥}$ Validation group.

complications. They also proposed that patients with those characteristics should be greatly encouraged to undergo liver biopsy so intervention can be offered [61]. The BAAT scoring system is calculated as the sum of the following parameters: age at liver biopsy ( $\geq 50$ years $=1$; $<50$ years $=0)$, BMI $\left(\geq 28 \mathrm{~kg} / \mathrm{m}^{2}=1 ;<28 \mathrm{~kg} / \mathrm{m}^{2}=0\right)$, triglycerides $(\geq 1.7 \mathrm{mmol} / \mathrm{L}=1 ;<1.7 \mathrm{mmol} / \mathrm{L}=0)$, and ALT ( $\geq 2$ times of normal $=1 ;<2$ times of normal $=0$ ). A score of 0 or 1 had $100 \%$ NPV for the diagnosis of septal fibrosis and cirrhosis [62]. The European Liver Fibrosis Group studied 1021 subjects who had a variety of chronic liver diseases and came up with the Original European Liver Fibrosis panel (OELF). The panel consists of age and three serum markers, HA, TIMP1, and PIIINP. For NAFLD, fibrosis stage 3 or 4 was detectable using a threshold value of 0.375 with a sensitivity of $89 \%$, specificity of $96 \%$, PPV of $80 \%$, and NPV of $98 \%$ [63]. The Enhanced Liver Fibrosis panel (ELF) differs from the 
OELF by simply removing age from the panel. Despite that change, the ELF had an excellent AUROC of 0.90 for distinguishing severe fibrosis (F0-2 vs. F3-4), good performance (AUROC 0.82) for moderate fibrosis (F0-1 vs. F2-4), and fair performance (AUROC 0.76) for no fibrosis (F0 vs. F1-4). By using the ELF, Guha et al. reported that $82 \%$ of liver biopsies in their study could be potentially avoided for the diagnosis of severe fibrosis [64].

The commercially available FibroTest incorporates five serum markers, $\alpha 2$ macroglobulin, haptoglobin, apolipoprotein A1, gamma-glutamyl transpeptidase (GGT), and total bilirubin. It has a good performance for detecting F2 (AUROC 0.81) and F3 (AUROC 0.88) fibrosis. The probability of cirrhosis is very low when the test score is below 0.3. On the other hand, the patient should be managed as a patient with cirrhosis when the score is 0.7 or higher [65]. By simply using ALT and glycosylated hemoglobin A1C, Gholam et al. reported an excellent performance (AUROC 0.90) of their model for detection of liver fibrosis in severely obese subjects $\left(\mathrm{BMI} \geq 40 \mathrm{~kg} / \mathrm{m}^{2}\right)$ [51].

The NAFLD Fibrosis Score (NFS) was developed from a large cohort $(n=773)$ and is calculated from six variables: age, hyperglycemia, BMI, platelet count, albumin, and AST/ALT ratio. By applying the low cutoff score (-1.455), advanced fibrosis could be excluded with high accuracy (NPV of $93 \%$ and $88 \%$ in the estimation and validation groups, respectively). By applying the high cutoff score (0.676), the presence of advanced fibrosis could be diagnosed with high accuracy (PPV of $90 \%$ and $82 \%$ in the estimation and validation groups, respectively). By using this model, Angulo et al. reported that a liver biopsy would have been avoided in $75 \%$ of the study cohort and with a correct prediction of $90 \%$ [66]. Since being published, the NFS has been directly compared with several other models. For example, the easily calculated BARD score was reported to be at least equivalent to the more complex NFS in excluding patients with advanced fibrosis [67]. Depending on the presence of the following variables, $\mathrm{BMI} \geq 28 \mathrm{~kg} / \mathrm{m}^{2}$ (1 point), AST/ALT ratio $\geq 0.8$ ( 2 points), and diabetes (1 point), the BARD score ranges from 0 to 4 . A score of 2-4 was associated with an OR for advanced fibrosis of 17 (95\% CI 9.2-31.9) and a NPV of $96 \%$. The BARD score seems to be more accurate at predicting advanced fibrosis in non-diabetics compared with diabetic patients [67]. The Fibrometer NAFLD, which is computed from seven easily obtainable variables (glucose, AST, ferritin, platelet, ALT, body weight and age), was reported to be more accurate than the NFS [68]. The FIB4 index was reported outperforming seven other noninvasive markers of fibrosis in patients with NAFLD, including the NFS, based on the analysis of a multi-center cohort [69]. A FIB4 index $\geq 2.67$ had an $80 \%$ PPV and a FIB4 index $\leq 1.30$ had a $90 \% \mathrm{NPV}$ of significant liver fibrosis [69]. As mentioned previously, the NAFIC score was developed based on a large Japanese cohort [59]. After a direct comparison, it was concluded that the easily determined NAFIC score was at least equivalent to the more complex NFS. The authors further suggested that liver biopsy can be avoided in NAFLD patients with a NAFIC score of 0 or 1 because they are likely to have NAFLD without advanced fibrosis. In contrast, liver biopsy should be recommended in NAFLD patients with an NAFIC score of $\geq 2$ to assess the extent of hepatic fibrosis and predict prognosis [59]. Finally, the NAFLD Diagnostic Panel was directly compared with the NFS in a recent study with a much smaller cohort [60]. For predicting either any degree of fibrosis or advanced fibrosis, the NAFLD Diagnostic Panel performed significantly better than that of the combined ELF and NFS model and ELF alone or NFS alone (any fibrosis and advanced fibrosis AUROC, 0.80 and 0.81, 0.78 and 0.63, 0.76 and 0.65, 0.71 and 0.59 , respectively) [60].

In summary, several diagnostic panels have been developed for the prediction of NASH and significant fibrosis in patients with NAFLD. Each panel is unique for its biomarker composition. The cohorts in different studies were heterogeneous in characteristics and sometimes highly selected, which may limit their utility in different populations. The recent published practice guideline recommends the NFS as a clinically useful tool for identifying NAFLD patients with higher likelihood of having bridging fibrosis and/or cirrhosis. In addition, the presence of MetS and the NFS may be used for identifying patients who are at risk for steatohepatitis and advanced fibrosis [70].

\section{Biomarkers for NAFLD defined by proteomic studies}

Using the promising proteomics, a few studies have been conducted to identify potential biomarkers for NAFLD. By studying bariatric surgery patients $(n=98)$, Younossi et al. first found 12 protein peaks with significant differential expression when sera from NAFLD groups $(n=91)$ were compared with obese controls $(n=7)$ [71]. A prospective study identified three protein peaks, which were related to different hemoglobin subunits, progressively increased in intensity from patients who were obese but without liver lesions $(n=24)$ to those with steatosis $(n=32)$ and NASH $(n=24)$, but returned to near normal value after patients had lost weight [72]. Bell et al. reported the expression levels of 55 and 15 proteins changed significantly between the simple steatosis $(\mathrm{n}=24)$ and NASH with advanced fibrosis $(\mathrm{n}=22)$ groups and the NASH $(n=23)$ and NASH with advanced fibrosis groups, respectively. There were, however, no significant differences observed between the simple steatosis and NASH groups, suggesting that systemic markers of fatty liver and NASH may not be present in serum from 
patients with mild disease [73]. Those proteins were found to be involved in immune regulation and inflammation, coagulation, cellular and extracellular matrix structure and function, and roles as carrier proteins in the blood [73].

In addition to sera, proteomics have also been used in other tissues to discover biomarkers for NAFLD. By studying liver specimens from severely obese patients, Charlton et al. discovered nine proteins with differential expression between study groups [74]. Lumican, a 40-kDa keratin sulfate proteoglycan that regulates collagen fibril assembly and activates transforming growth factor-beta and smooth muscle actin, was overexpressed in a progressive manner in NASH-mild versus simple steatosis (124\%, $\mathrm{p}<0.001$ ), NASH-progressive versus NASH-mild (156\%, $\mathrm{p}<0.001)$, and NASH-progressive versus obese normal $(178 \%, \mathrm{p}<0.001)$. Fatty acid binding protein -1 , which is protective against the detergent effects of excess fatty acids, was underexpressed in NASH-mild versus simple steatosis $(73 \%, \mathrm{p}<0.001), \mathrm{NASH}$-progressive versus NASH-mild (81\%, p<0.001), and NASH-progressive versus obese normal $(59 \%, \mathrm{p}<0.001)$ [74]. Another study analyzed liver samples from severely obese patients and identified two candidate markers, CPS1 and GRP78, which were down-regulated in NASH versus normal control groups [75]. CPS1 and GRP78 were also confirmed to be serum candidate markers of NAFLD. Their serum concentrations decreased gradually from control subjects to steatosis and NASH patients [75]. By studying visceral adipose tissue, Younossi et al. reported that a model based on a combination of clinical and phosphoproteomic parameters had a good performance in predicting NASH (AUROC 0.86 , sensitivity $81.3 \%$, specificity $87 \%$ ) [76].

In contrast to the previous reports, Ulukaya et al. reported that serum proteomic pattern analysis did not help to distinguish NASH from simple steatosis in patients with NAFLD [77]. Compared to the prior studies, the study subjects had a much lower BMI, which may explain the disparity.

In summary, proteomics is a promising technology that can screen a large number of proteins in a high throughput fashion. The use of proteomics in discovery of biomarkers for NAFLD is still in early stages. Most of the data mentioned in this section were derived from severely obese subjects who were mainly Caucasians. The findings need to be validated in other population in the future.

\section{Conclusion}

Several biomarkers that are associated with inflammation, ECM, and apoptosis have been individually studied for their performances in distinguishing NASH from simple steatosis. Routine use of individual marker is limited by the controversial published results and commercial unavailability. Several panels of biomarkers in variable combination have been developed for the detection of either NASH and/or advanced liver fibrosis. Most of the panels have not been validated in longitudinal studies. The study cohorts are heterogeneous in characteristics and sometimes highly selected. Future studies should be ideally designed as population-based, prospective, and longitudinal in order to eliminate selection and referral biases and to validate the results derived from cross-sectional studies.

\section{Competing interests}

The authors declare that they have no competing interests.

\section{Authors' contributions}

SP, NT and JP drafted the manuscript. All authors read and approved the final manuscript.

\section{Received: 9 November 2012 Accepted: 4 January 2013}

Published: 4 February 2013

\section{References}

1. Angulo P: Nonalcoholic fatty liver disease. N Engl J Med 2002, 346:1221-1231.

2. Wieckowska A, Feldstein AE: Nonalcoholic fatty liver disease in the pediatric population: a review. Curr Opin Pediatr 2005, 17:636-641.

3. Ekstedt M, Franzen LE, Mathiesen UL, Thorelius L, Holmqvist M, Bodemar G, Kechagias S: Long-term follow-up of patients with NAFLD and elevated liver enzymes. Hepatology 2006, 44:865-873.

4. Xie L, Yui J, Hatori A, Yamasaki T, Kumata K, Wakizaka H, Yoshida Y, Fujinaga M, Kawamura K, Zhang MR: Translocator protein (18 kDa), a potential molecular imaging biomarker for non-invasively distinguishing nonalcoholic fatty liver disease. J Hepatol 2012, 57:1076-1082.

5. Soderberg C, Stal P, Askling J, Glaumann H, Lindberg G, Marmur J, Hultcrantz R: Decreased survival of subjects with elevated liver function tests during a 28-year follow-up. Hepatology 2010, 51:595-602

6. Wieckowska A, McCullough AJ, Feldstein AE: Noninvasive diagnosis and monitoring of nonalcoholic steatohepatitis: present and future. Hepatology 2007, 46:582-589.

7. Browning JD, Szczpaniak LS, Dobbins R, Nuremberg P, Horton JD, Cohen JC, Grundy SM, Hobbs HH: Prevalence of hepatic steatosis in an urban population in the United States: impact of ethnicity. Hepatology 2004, 40:1387-1395

8. Sorrentino P, Tarantino G, Conca P, Perrella A, Terracciano ML, Vecchione R, Gargiulo G, Gennarelli N, Lobello R: Silent non-alcoholic fatty liver diseasea clinical-histological study. J Hepatol 2004, 41:751-757.

9. Mofrad P, Contos MJ, Haque M, Sargeant C, Fisher RA, Luketic VA, Sterling RK, Shiffman ML, Stravitz RT, Sanyal AJ: Clinical and histologic spectrum of nonalcoholic fatty liver disease associated with normal ALT values. Hepatology 2003, 37:1286-1292.

10. de Alwis NM, Day CP: Non-alcoholic fatty liver disease: the mist gradually clears. J Hepatol 2008, 48(Suppl 1):S104-S112.

11. Romeo GR, Lee J, Shoelson SE: Metabolic syndrome, insulin resistance, and roles of inflammation - mechanisms and therapeutic target. Arterioscler Thromb Vasc Biol 2012, 32:1771-1776.

12. Kleiner DE, Brunt EM, Natta MV, Behling C, Contos MJ, Cummings OW, Ferrell LD, Liu YC, Torbenson MS, Unalp-Arida A, Yeh M, McCullough AJ, Sanyal A: Design and validation of a histological scoring system for nonalcoholic fatty liver disease. Hepatology 2005, 41:1313-1321.

13. Hotamisligil GS, Budavari A, Murray D, Spiegelman BM: Reduced tyrosine kinase activity of the insulin receptor in obesity-diabebes. J Clin Invest 1994, 94:1543-1549.

14. Abiru S, Migita K, Maeda Y, Daikoku M, Ito M, Ohata K, Nagaoka S, Matsumoto T, Takii Y, Kusumoto K, Nakamura M, Komori A, Yano K, Yatsuhashi $H$, Eguchi $K$, Ishibashi $H$ : Serum cytokine and soluble cytokine receptor levels in patients with non-alcoholic steatohepatitis. Liver Int 2006, 26:39-45.

15. Alaaeddine N, Sidaoui J, Hilal G, Serhal R, Abedelrahman A, Khoury S: TNFalpha messenger ribonucleic acid (mRNA) in patients with nonalcoholic steatohepatitis. Eur Cytokine Netw 2012, 23:107-111. 
16. Satapathy SK, Garg S, Chauhan R, Sakhuja P, Malhotra V, Sharma BC, Sarin SK: Beneficial effects of tumor necrosis factor-alpha inhibition by pentoxyfilline on clinical, biochemical, and metabolic parameters of patients with nonalcoholic steatohepatitis. Am J Gastroenterol 2004, 99:1946-1952

17. Satapathy SK, Sakhuja P, Malhotra V, Shamrma BC, Sarin SK: Beneficial effects of pentoxyfilline on hepatic steatosis, fibrosis and necroinflammation in patients with non-alcoholic steatohepatitis. J Gastroenterol Hepatol 2007, 22:634-638.

18. Zein CO, Yerian LM, Gogate P, Lopez R, Kirwan JP, Feldstein AE, McCullough AJ: Pentoxifylline improves nonalcoholic steatohepatitis: a randomized placebo-controlled trial. Hepatology 2011, 54:1610-1619.

19. Senn JJ, Klover PJ, Nowak IA, Zimmers TA, Koniaris LG, Furlanetto RW, Mooney RA: Suppressor of cytokine signaling-3 (SOCS-3), a potential mediator of interleukin-6-dependent insulin resistance in hepatolocytes. J Biol Chem 2003, 278:13740-13746

20. Kugelmas M, Hill DB, Vivian B, Marsano L, McClain CJ: Cytokines and NASH: pilot study of the effects of lifestyle modification and vitamin $E$. Hepatology 2003, 38:413-419.

21. Garcia-Galiano D, Sanchez-Garrido MA, Espejo I, Montero JL, Costan G, Marchal T, Membrives A, Gallardo-Valverde JM, Munoz-Castaneda JR, Arevalo De la Mata M, Muntane J: IL-6 and IGF-1 are independent prognostic factors of liver steatosis and non-alcoholic steatohepatitis in morbidly obese patients. Obes Surg 2007, 17:493-503.

22. Tarantino G, Conca P, Pasanisi F, Ariello M, Mastrolia M, Arena A, Tarantino M, Scopacasa F, Vecchione R: Could inflammatory markers help diagnose nonalcoholic steatohepatitis? Eur J Gastroenterol Hepatol 2009, 21:504-511.

23. Park SH, Kim BI, Yun JW, Kim JW, Park DI, Cho YK, Sung IK, Park CY, Sohn Cl, Jeon WK, Kim H, Rhee EJ, Lee WY, Kim SW: Insulin resistance and creactive protein as independent risk factors for non-alcoholic fatty liver disease in non-obese Asian men. J Gastroenterol Hepatol 2004, 19:694-698.

24. Yoneda M, Mawatari H, Fujita K, lida H, Yonemitsu K, Kato S, Takahashi H, Kirikoshi H, Inamori M, Nozaki Y, Abe Y, Kubota K, Saito S, Iwasaki T, Terauchi Y, Togo S, Maeyama S, Nakajima A: High-sensitivity c-reactive protein is an independent clinical feature of nonalcoholic steatohepatitis (NASH) and also of the severity of fibrosis in NASH. J Gastroenterol 2007, 42:573-582.

25. Fierbinteanu-Braticevici C, Baicus C, Tribus L, Papacocea R: Predictive factors for nonalcoholic steatohepatitis (NASH) in patients with nonalcoholic fatty liver disease (NAFLD). J Gastrointestin Liver Dis 2011, 20:153-159.

26. Koruk M, Taysi S, Savas MC, Yilmaz O, Akcay F, Karakok M: Serum levels of acute phase proteins in patients with nonalcoholic steatohepatitis. Turk J Gastroenterol 2003, 14:12-17.

27. Hui JM, Farrell GC, Kench JG, George J: High sensitivity c-reactive protein values do not reliably predict the severity of histological changes in NAFLD. Hepatology 2004, 39:1458-1459.

28. Zimmermann E, Anty R, Tordjman J, Verrijken A, Gual P, Tran A, lannelli A, Gugenheim J, Bedossa P, Francque S, Marchand-Brustel YL, Clement K, Gaal $L V$, Sorensen T, Jess T: C-reactive protein levels in relation to various features of non-alcoholic fatty liver disease among obese patients. J Hepatol 2011, 55:660-665.

29. Yoneda M, Uchiyama T, Kato S, Endo H, Fujita K, Yoneda K, Mawatari H, ljda H, Takahashi H, Kirikoshi H, Inamori M, Nozaki Y, Kobayashi N, Kubota K, Saito S, Maeyama S, Saraga M, Aburatani H, Kodama T, Nakajima A: Plasma pentraxin3 is a novel marker for nonalcoholic steatohepatitis. BMC Gastroentero/ 2008, 8:53

30. Fargion S, Mattioli M, Fracanzani AL, Sampietro M, Tavazzi D, Fociani P, Taioli E, Valenti L, Fiorelli G: Hyperferritinemia, iron overload, and multiple metabolic alterations identify patients at risk for nonalcoholic steatohepatitis. Am J Gastroenterol 2001, 96:2448-2455.

31. Yoneda M, Nozaki Y, Endo H, Mawatari H, lida H, Fujita $K$, Yoneda K, Takahashi H, Kirikoshi H, Inamori M, Kobayashi N, Kubota K, Saito S, Maeyama S, Hotta K, Nakajima A: Serum ferritin is a clinical biomarker in Japanese patients with nonalcoholic steatohepatitis (NASH) independent of HFE gene mutation. Dig Dis Sci 2010, 55:808-814

32. Manousou P, Kalambokis G, Grillo F, Watkins J, Xirouchakis E, Pleguezuelo M, Leandro G, Arvaniti V, Germani G, Patch D, Calvaruso V, Mikhailidis DP, Dhillon AP, Burroughs AK: Serum ferritin is a discriminant marker for both fibrosis and inflammation in histologically proven non-alcoholic fatty liver disease patients. Liver Int 2011, 31:730-739.

33. Kowdley KV, Belt P, Wilson LA, Yeh MM, Neuschwander-Tetri BA, Chalasani $\mathrm{N}$, Sanyal AJ, Nelson JE: Serum ferritin is an independent predictor of histologic severity and advanced fibrosis in patients with nonalcoholic fatty liver disease. Hepatology 2012, 55:77-85.

34. Chandok N, Minuk G, Wengiel M, Uhanova J: Serum ferritin levels do not predict the stage of underlying non-alcoholic fatty liver disease. J Gastrointestin Liver Dis 2012, 21:53-58.

35. Sakugawa H, Nakayoshi T, Kobashigawa K, Yamashiro T, Maeshiro T, Miyagi S, Shiroma J, Toyama A, Nakayoshi T, Kinjo F, Saito A: Clinical usefulness of biochemical markers of liver fibrosis in patients with nonalcoholic fatty liver disease. World J Gastroenterol 2005, 11:255-259.

36. Lydatakis H, Hager IP, Kostadelou E, Mpousmpoulas S, Pappas S, Diamantis I: Non-invasive markers to predict the liver fibrosis in non-alcoholic fatty liver disease. Liver Int 2006, 26:864-871.

37. Malik R, Chang M, Bhaskar K, Nasser I, Curry M, Schuppan D, Byrnes V, Afdhal N: The clinical utility of biomarkers and the nonalcoholic steatohepatitis CRN liver biopsy scoring system in patients with nonalcoholic fatty liver disease. J Gastroenterol Hepatol 2009, 24:564-568.

38. Tanwar S, Trembling PM, Guha IN, Parkes J, Kaye P, Burt AD, Ryder SD, Aitha GP, Day CP, Rosenberg WM: Validation of PIIINP for the detection and assessment of non-alcoholic steatohepatitis in patients with nonalcoholic fatty liver disease. Hepatology 2012, [Epub ahead of print].

39. Feldstein $A E$, Canbay $A$, Angulo $P$, Taniai M, Burgart $L J$, Lindor KD, Gores G]: Hepatocyte apoptosis and Fas expression are prominent features of human nonalcoholic steatohepatitis. Gastroenterology 2003, 125:437-443.

40. Feldstein $A E$, Gores $G J$ : Apoptosis in alcoholic and nonalcoholic steatohepatitis. Front Biosci 2005, 10:3093-3099.

41. Wieckowska A, Zein NN, Yerian LM, Lopez AR, McCullough AJ, Feldstein AE: In vivo assessment of liver cell apoptosis as a novel biomarker of disease severity in nonalcoholic fatty liver disease. Hepatology 2006, 44:27-33.

42. Feldstein AE, Wieckowska A, Lopez AR, Liu YC, Zein NN, McCullough AJ: Cytokeratin-18 fragment levels as noninvasive biomarkers for nonalcoholic steatohepatitis: a multicenter validation study. Hepatology 2009, 50:1072-1078.

43. Papatheodoridis GV, Hadziyannis E, Tsochatzis E, Georgiou A, Kafiri G, Tiniakos DG, Margariti K, Manolakopoulos S, Manesis EK, Archimandritis AJ: Serum apoptotic caspase activity in chronic hepatitis $C$ and nonalcoholic fatty liver disease. J Clin Gastroenterol 2010, 44:e87-e95.

44. Tsutsui M, Tanaka N, Kawakubo M, Sheena Y, Horiuchi A, Komatsu M, Nagaya T, Joshita S, Umemura T, Ichijo T, Matsumoto A, Yoshizawa K, Aoyama T, Tanaka E, Sano K: Serum fragmented cytokeratin 18 levels reflect the histologic activity score of nonalcoholic fatty liver disease more accurately than serum alanine aminotransferase levels. J Clin Gastroenterol 2010, 44:440-447.

45. Yilmaz Y, Dolar E, Ulukaya E, Akgoz S, Keskin M, Kiyici M, Aker S, Yilmaztepe A, Gurel S, Gulten M, Nak SG: Soluble forms of extracellular cytokeratin 18 may differentiate simple steatosis from nonalcoholic steatohepatitis. World J Gastroenterol 2007, 13:837-844.

46. Shen J, Chan HL, Wong GL, Choi PC, Chan AW, Chan HY, Chim AM, Yeung DK, Chan FK, Woo J, Yu J, Chu WC, Wong WW: Non-invasive diagnosis of non-alcoholic steatohepatitis by combined serum biomarkers. $J$ Hepatol 2012, 56:1363-1370

47. Joka D, Wahl K, Moeller S, Schlue J, Vaske B, Bahr MJ, Manns MP, SchulzeOsthoff K, Bantel H: Prospective biopsy-controlled evaluation of cell death biomarkers for prediction of liver fibrosis and nonalcoholic steatohepatitis. Hepatology 2012, 55:455-464.

48. Dixon JB, Bhathal PS, O'Brien PE: Nonalcoholic fatty liver disease: predictors of nonalcoholic steatohepatitis and liver fibrosis in the severely obese. Gastroenterology 2001, 121:91-100.

49. Palekar NA, Naus R, Larson SP, Ward J, Harrison SA: Clinical model for distinguishing nonalcoholic steatohepatitis from simple steatosis in patients with nonalcoholic fatty liver disease. Liver Int 2006, 26:151-156.

50. Poynard T, Ratziu V, Charlotte F, Messous D, Munteanu M, Imbert-Bismut F, Massard J, Bonyhay L, Tahiri M, Thabut D, Cadranel JF, Le Bail B, de Ledinghen V, LIDO Study Group, CYTOL study group: Diagnostic value of biochemical markers (NashTest) for the prediction of nonalcoholic steatohepatitis in patients with non-alcoholic fatty liver disease. BMC Gastroenterol 2006, 6:34.

51. Gholam PM, Flancbaum L, Machan JT, Charney DA, Kotler DP: Nonalcoholic fatty liver disease in severely obese subjects. Am J Gastroenterol 2007, 102:399-408.

52. Campos GM, Bambha K, Vittinghoff E, Rabl C, Posselt AM, Ciovica R, Tiwari $U$, Ferrel L, Pabst M, Bass NM, Merriman RB: A clinical scoring system for 
predicting nonalcoholic steatohepatitis in morbidly obese patients. Hepatology 2008, 47:1916-1923.

53. Ulitsky A, Ananthakrishnan AN, Komorowski R, Wallace J, Surapaneni SN, Franco J, Saeian K, Gawrieh S: A noninvasive clinical scoring model predicts risk of nonalcoholic steatohepatitis in morbidly obese patients. Obes Surg 2010, 20:685-691.

54. Shimada M, Kawahara H, Ozaki K, Fukura M, Yano H, Tsuchishima M, Tsutsumi M, Takase S: Usefulness of a combined evaluation of the serum adiponectin level, HOMA-IR, and serum type IV collage $7 \mathrm{~S}$ level to predict the early stage of nonalcoholic steatohepatitis. Am J Gastroenterol 2007, 102:1931-1938.

55. Deng Y, Scherer PE: Adipokines as novel biomarkers and regulators of the metabolic syndrome. Ann NY Acad Sci 2010, 1212:E1-E19.

56. Tarek I, Tamimi AR, Elogouhari HM, Alkhouri N, Yerian M, Berk MP, Lopez R, Schauer PR, Zein NN, Feldstein AE: An apoptosis panel for nonalcoholic steatohepatitis diagnosis. J Hepatol 2011, 54:1224-1229.

57. Younossi ZM, Jarrar M, Nugent C, Randhawa M, Afendy M, Stepanova M, Rafiq N, Goodman Z, Chandhoke V, Baranova A: A novel diagnostic biomarker panel for obesity-related nonalcoholic steatohepatitis (NASH). Obes Surg 2008, 18:1430-1437.

58. Sookoian S, Castano G, Burgueno AL, Gianotti TF, Rosselli MS, Pirola CJ: A diagnostic model to differentiate simple steatosis from nonalcoholic steatohepatitis based on the likelihood ratio form of Bayes theorem. Clin Biochem 2009, 42:624-629.

59. Sumida $Y$, Yoneda $M$, Hyogo $H$, Yamaguchi $K$, Ono M, Fujii H, Eguchi $Y$, Suzuki Y, Imai S, Kanemasa K, Fujita K, Chayama K, Yasui K, Saibara T, Kawada N, Fujimoto K, Kohgo Y, Okanoue T, Japan Study Group of Nonalcoholic Fatty Liver Disease (JSG-NAFLD): A simple clinical scoring system using ferritin, fasting insulin, and type IV collagen $7 \mathrm{~S}$ for predicting steatohepatitis in nonalcoholic fatty liver disease. J Gastroenterol 2011, 46:257-268.

60. Younossi Z, Page S, Rafiq N, Birerdinc A, Stepanova M, Hossain N, Afendy A, Younoszai Z, Goodman Z, Baranova A: A biomarker panel for nonalcoholic steatohepatitis (NASH) and NASH-related fibrosis. Obes Surg 2011, 21:431-439.

61. Angulo P, Keach JC, Batts KP, Lindor KD: Independent predictor of liver fibrosis in patients with nonalcoholic steatohepatitis. Hepatology 1999, 30:1356-1362.

62. Ratziu V, Gira P, Charlotte F, Bruckert E, Thibault V, Theodorou I, Khalil L, Turpin G, Opolon P, Poynard T: Liver fibrosis in overweight patient. Gastroenterology 2000, 118:1117-1123.

63. Rosenberg WM, Voelker M, Thiel R, Becka M, Burt A, Schuppan D, Hubscher S, Roskams T, Pinzani M, Atrhur MJ, European Liver Fibrosis Group: Serum markers detect the presence of liver fibrosis: a cohort study. Gastroenterology 2004, 127:1704-1713.

64. Guha IN, Parkes J, Rodreick P, Chattopadhyay D, Cross R, Harris S, Kaye P, Burt AD, Ryder SD, Aithal GP, Day CP, Rosenberg WM: Noninvasive markers of fibrosis in nonalcoholic fatty liver disease: validating the European Liver Fibrosis Panel and exploring simple markers. Hepatology 2008, 47:455-460.

65. Ratziu V, Massard J, Charlotte F, Messous D, Imbert-Bismut F, Bonyhay L, Tahiri M, Munteanu M, Thabut D, Cadranel JF, Le Bail B, de Ledinghen V, Poynard T, LIDO Study Group, CYTO study group: Diagnostic value of biochemical markers (FibroTest-FibroSURE) for the prediction of liver fibrosis in patients with non-alcoholic fatty liver disease. BMC Gastroenterol 2006, 6:6.

66. Angulo P, Hui JM, Marchesini G, Bugianesi E, George J, Farrell GC, Enders F, Saksena S, Burt AD, Bida JP, Lindor K, Sanderson SO, Lenzi M, Adams LA, Kench J, Therneau TM, Day CP: The NAFLD fibrosis score: a noninvasive system that identifies liver fibrosis in patients with NAFLD. Hepatology 2007, 45:846-854.

67. Harrison SA, Oliver D, Arnod HL, Gogia S, Neuschwander-Tetri BA: Development and validation of a simple NAFLD clinical scoring system for identifying patients without advanced disease. Gut 2008, 57:1441-1447

68. Cales P, Laine F, Boursier J, Deugnier Y, Moal V, Oberti F, Hunault G, Rousselet MC, Hubert I, Laafi J, Ducluzeaux PH, Lunel F: Comparison of blood tests for liver fibrosis specific or not to NAFLD. J Hepatol 2009, 50:165-173.

69. Shah A, Lydecker A, Murray K, Tetri BN, Contos MJ, Sanyal AJ, Nash Clinical Research Network: Comparison of noninvasive markers of fibrosis in patients with nonalcoholic fatty liver disease. Clin Gastroenterol Hepatol 2009, 7:1104-1112.

70. Chalasani N, Younossi Z, Lavine JE, Diehl AM, Brunt EM, Cusi K, Charlton M, Sanyal AJ: The diagnosis and management of non-alcoholic fatty liver disease: practice guideline by the American association for the study of liver diseases, American College of Gastroenterology, and the American Gastroenterological Association. Hepatology 2012, 55:2005-2023.

71. Younossi ZM, Baranova A, Ziegler K, Del Giacco L, Schlauch K, Born TL, Elariny H, Gorreta F, VanMeter A, Younoszai A, Ong JP, Goodman Z, Chandhoke V: A genomic and proteomic study of the spectrum of nonalcoholic fatty liver disease. Hepatology 2005, 42:665-674.

72. Trak-Smayra V, Dargere D, Noun R, Albuquerque M, Yaghi C, Gannage-Yared $\mathrm{MH}$, Bedossa P, Paradis V: Serum proteomic profiling of obese patients: correlation with liver pathology and evolution after bariatric surgery. Gut 2009, 58:825-832.

73. Bell LN, Theodorakis JL, Vuppalanchi R, Saxena R, Bemis KG, Wang M, Chalasani N: Serum proteomics and biomarker discovery across the spectrum of nonalcoholic fatty liver disease. Hepatology 2010, 51:111-120.

74. Charlton M, Viker K, Krishnan A, Sanderson S, Veldt B, Kaalsbeek AJ, Kendrick M, Thompson G, Que F, Swain J, Sarr M: Differential expression of lumican and fatty acid binding protein-1: new insights into the histologic spectrum of nonalcoholic fatty liver disease. Hepatology 2009 49:1375-1384

75. Rodriguez-Suarez E, Duce AM, Caballeria J, Arrieta FM, Fernandez E, Gomara C, Alkorta N, Ariz U, Martinez-Chantar ML, Lu SC, Elortza F, Mato JM: Nonalcoholic fatty liver disease proteomics. Proteomics Clin Appl 2010, 4:362-371

76. Younossi ZM, Varanova A, Stepanova M, Page S, Calvert VS, Afendy A, Goodman Z, Chandhoke V, Liotta L, Petricoin E: Phosphoproteomic biomarkers predicting histologic nonalcoholic steatohepatitis and fibrosis. J Proteome Res 2010, 9:3218-3224.

77. Ulukaya E, Yilmaz Y, Moshkovskii S, Karpova M, Pyatnitskiy M, Atug O, Dolar E: Proteomic analysis of serum in patients with non-alcoholic steatohepatitis using matrix-assisted laser desorption ionization time-offlight mass spectrometry. Scand J Gastroenterol 2009, 44:1471-1476.

doi:10.1186/2050-7771-1-7

Cite this article as: Pearce et al:: Noninvasive biomarkers for the diagnosis of steatohepatitis and advanced fibrosis in NAFLD. Biomarker Research 2013 1:7.

\section{Submit your next manuscript to BioMed Central and take full advantage of:}

- Convenient online submission

- Thorough peer review

- No space constraints or color figure charges

- Immediate publication on acceptance

- Inclusion in PubMed, CAS, Scopus and Google Scholar

- Research which is freely available for redistribution 